\title{
Osteoid Osteoma of Proximal Phalanx of the Index Finger of the Right Hand
}

\author{
Seyed Abdolhossein Mehdi Nasab ${ }^{1}$, Mohammad Pipelzadeh ${ }^{2}$ \\ ${ }^{1}$ Department of Orthopedic Surgery, Imam Khomeini Hospital, Jundishapur University of Medical Sciences, \\ Ahvaz, Iran \\ ${ }^{2}$ Clinical Research Center, Jundishapur University of Medical Sciences, Ahvaz, Iran \\ E-mail: \{hmehdinasab, mpipel\}@yahoo.com \\ Received October 3, 2011; revised December 1, 2011; accepted December 11, 2011
}

\begin{abstract}
Osteoid osteoma is a benign bone forming tumor of the growing skeleton that is most often seen in young men. It represents by pain and radiologic appearance of anidus surrounded by osteosclerosisthat occurs mostly in long bones of the lower extremity. Occurrence of this tumor in the hand is an uncommon condition. We present a 23-year-old man with an osteoid osteoma in the proximal phalanx of the right index finger. The radiological examination showed a lytic lesion with irregular border with a central sclerotic nidus and also sclerotic changes around the lytic lesion and bone expansion in the proximal phalanx of the right index finger. He was suffering from a history of pain and swelling of his finger since 8 months. The pain disappeared after surgical excision of nidus. The patient was pain-free and there was no evidence of recurrence at 15 months follow up.
\end{abstract}

Keywords: Osteoid Osteoma, Phalanx, Hand

\section{Introduction}

Osteoid osteoma is a benign osteoblastic tumor first described by Jaffe in 1835 . It accounts for about $11 \%$ of benign tumors and $3 \%$ of all primary bone tumors with $6 \%$ to $13 \%$ of all cases occurring in the hand [1]. This tumor usually affects children, adolescents and young adults, but $90 \%$ of cases occur in patients younger than 25 years old. Male-female ratio for osteoid osteoma is 2:1. Pain, worse at night and relieved by oral non-steroidal anti-inflammatory medications is the most typical symptom [2]. This tumor is most frequently seen in the metaphysis or diaphysis of long bones with half the cases involving the femur or tibia but it can affect the posterior element of the spine (10\%), hands or feet (12\%) [2]. Radiograph of the affected long bone shows a lucent area less than $1.5 \mathrm{~cm}$ in diameter called nidus surrounded by a zone of reactive bone formation in the cortical or medullary canal [3]. Osteoid osteomas of the hand areuncommon, most commonly seen in the phalanges, and often result in atypical clinical and radiologic findings. So, long delay in diagnosis is common since clinical findings may mimic a variety of diseases in differential diagnosis.

\section{Case History}

A 23 years old man was referred with a history of pain at proximal phalanx of index finger of his right hand since 8 months. No previous trauma was mentioned. He reported mild pain which progressively increased at night and responded partially with analgesic drugs. He had been treated with antibiotic as a case of infection, but the pain was unrelieved. Physical examination revealed tenderness and swelling at proximal phalanx of index finger. Some limitation in PIP joint was noted. The radiological examination showed a lytic lesion with irregular border with a central sclerotic nidus and also sclerotic changes around the lytic lesion and bone expansion in the proximal phalanx of the right index finger (Figure 1) and CT scan of fingers revealed a sclerotic expansile lesion in the proximal phalanx of the right index finger (Figure 2).

General condition and blood examination was normal. The patient underwent surgery under general anesthesia. Using a dorsolateral approach the cortex of proximal phalanx was opened and a soft reddish mass with central lesion was resected with a curette and sent for histopathologic examination. After high speed burr of the lesion the resulting bone defect was filled with autogenouscan- 


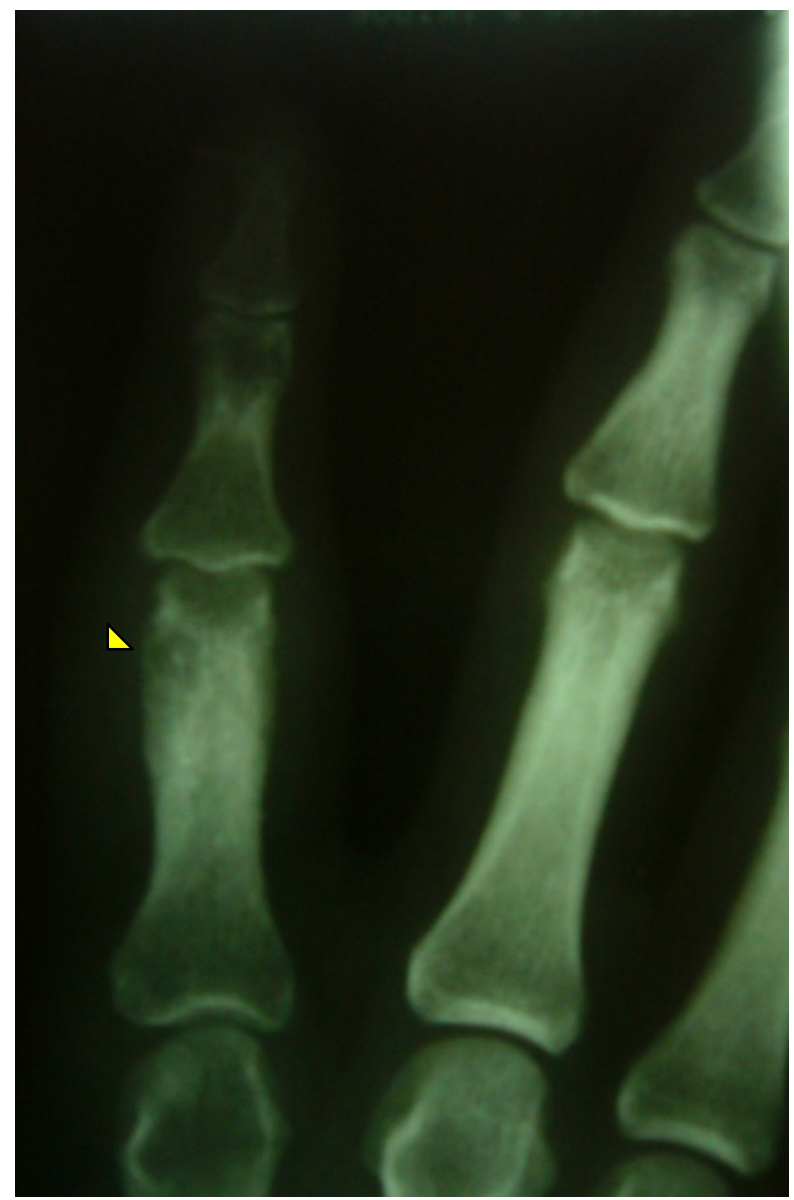

Figure 1. Anteroposterior radiograph of the right hand. The radiological examination showed a lytic lesion (arrow head) with irregular border with a central sclerotic nidus and also sclerotic changes around the lytic lesion and bone expansion in the proximal phalanx of the right index finger.

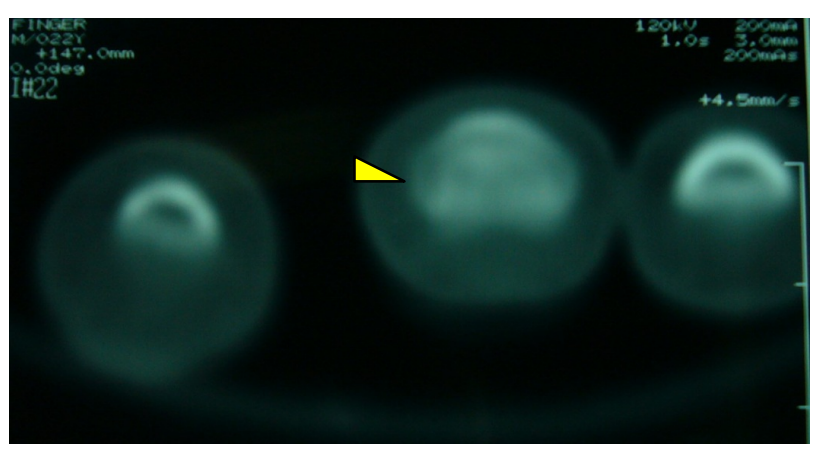

Figure 2. CT scan of fingers revealed a sclerotic expansile lesion (arrow head) in the proximal phalanx of the right index finger.

celous bone graft taken from theiliac crest. Histopathologic study revealed irregular trabeculae, immature osteoid, vascular connective tissue consisting of osteoid osteoma diagnosis. The pain was decreased in first day post operation and complete relief of pain was reported at one week after surgery. At final follow up 15 monthspost-surgery the patient was pain free with no sign of recurrence.

\section{Discussion}

Occurrence of osteoid osteoma in the hand is unusual and in order of frequency, proximal, distal and middle phalanx are the most frequent site. Diagnosis is based on clinical and plain radiography, in particular when the tumor occurs in its frequent site of proximal femur or tibia which has characteristic radiologic findings. Although the manifestations of osteoid osteoma in a typical patient are usually diagnostic, those occurring in phalanges of the handare frequently misdiagnosed [4,5]. This is partly because of their rarity in the hand and atypical manifestations [6].Plain radiography is usually sufficient to make the diagnosis but CT scan is the best modality to identify nidus and confirm the correct diagnosis $[3,6]$. Bone scans though nonspecific, can show a hot spot because of vascular character of this tumor. Meng et al. reported the most common appearance of osteoid osteoma of the hand is of an eccentric lesion with soft-tissue swelling and a relative absence of sclerosis, suggesting osteomyelitis [6]. Most of the hand osteoid osteomasare diagnosed late because of atypical radiologic or clinical findings. This tumor may be misdiagnosed with conditions such as subacute osteomelitis, Brodie's abscess, tuberculosis, tenosynovitis. Patients with osteoid osteomain the small bones of hand may present without pain or without anidus or bone forming reaction and this is the reason for delay in diagnosis. Although this tumor may regress spontaneously after a long time, but surgery is usually indicated in symptomatic patients not responsive to medical treatment. A variety of treatment options including medication, wide excision of the nidus and curettage of the lesion, CT-guided core drill excision, radionuclide-guided excision, percutaneous radiofrequency ablation, injection of ethanol, or interstitial laser photocoagulation (ILP) have been used for this tumor [3,7-11]. Percutaneous CT-guided ablations with laser or radiofrequency have now widely replaced surgery as the treatment of choice for osteoid osteoma. However, surgical excision still plays a major role for the lesions in the hands and feet owing to the close relationship of the small bones with the neurovascular structures [12,13].

\section{Conclusions}

In patients with pain, swelling and abnormal radiographic findings in the hand, osteoid osteoma should be considered in the differential diagnosis. Surgery is still the treatment of choice for phalangeal osteoid osteoma 
because of their close relationship with the neurovascular structures.

\section{References}

[1] G. Rubin, A. Wolovelsky, M. Rinott, and N. Rozen, “Osteoid Osteoma of the Hamate: An Unusual Cause of Ulnar-Sided Wrist Pain,” Orthopedics, Vol. 33, No. 7, 2010, p. 513.

[2] B. Galdi, J. T. Capo, A. Nourbakhsh and F. Patterson, "Osteoid Osteoma of the Thumb: A Case Report," Hand, Vol. 5, No. 4, 2010, pp. 423-426. doi:10.1007/s11552-010-9257-9

[3] R. K. Heck, "Benign Bone Tumors and Non Neoplastic Condition Simulation Bone Tumors,” In: S. Terrycanale, J. H. Beaty, Eds., Campbell's Operative Orthopedics, Mosby, Philadelphia, 2008, pp. 855-857.

[4] S. S. Bilgin, Y. Yildiz, B. Güçlü and Y. Saglik, "Osteoid Osteoma in the Hand: An Evaluation of Eight Patients," Acta Orthopaedica et Traumatologica Turcica, Vol. 38, No. 3, 2004, pp. 206-211.

[5] S. Agarwala and B. S. Rajput, "Osteoid Osteoma-Puzzling Presentation \& Effective Management-A Case Report,” Indian Journal of Orthopaedics, Vol. 38, No. 3, 2004, pp. 183-184.

[6] Q. Meng and L. Watt, "Phalangeal Osteoid Osteoma," British Journal of Radiology, Vol. 62, No. 736, 1989, pp. 321-325. doi:10.1259/0007-1285-62-736-321

[7] P. Goswami, N. Medhi, P. K. Sarma, H. S. Das and P. Hazarika, "Imaging Features of Osteoid Osteoma in Plain
Radiograph, CT and MR: A Case Report and Review of Literatures,” Indian Journal of Radiology and Imaging, Vol. 15, No. 4, 2005, pp. 481-484. doi:10.4103/0971-3026.28779

[8] C. Maynou, H. Baudson, A. Cotten and H. Mestdagh, "Osteoid Osteoma of the Radial Bicipital Tuberosity: Report of 2 Cases," Revue de Chirurgie Orthopedique et Reparatrice de Lappareil Moteur, Vol. 87, No. 6, 2001, pp. 606-609.

[9] A. A. Essi, N. Hattoma, A. Grane, N. Adnane, M. Rafai, A. Largab and M. Trafeh, "Badly-Known Osteoid Osteoma of the Phalanx (Case Report)," The Pan Arab Journal of Orthopaedics and Trauma, Vol. 8, No. 1, 2004, pp. 91-93

[10] I. Ghanem, "The Management of Osteoid Osteoma: Updates and Controversies," Current Opinion in Pediatrics, Vol. 18, No. 1, 2006, pp. 36-41. doi:10.1097/01.mop.0000193277.47119.15

[11] J. M. Soler, G. Piza and F. Aliaga, "Special Characteristics of Osteoid Osteoma in the Proximal Phalanx," Journal of Hand Surgery, Vol. 22, No. 6, 1997, pp. 793-797. doi:10.1016/S0266-7681(97)80451-2

[12] M. Soong, J. Jupiter and D. Rosenthal, "Radio Frequency Ablation of Osteoid Osteoma in the Upper Extremity," Journal of Hand Surgery, Vol. 31, No. 2, 2006, pp. 279283. doi:10.1016/j.jhsa.2005.10.012

[13] C. C. Harrod, R. E. Boykin and J. B. Jupiter, "Pain and Swelling after Radiofrequency Treatment of Proximal Phalanx Osteoid Osteoma: Case Report,” Journal of Hand Surgery, Vol. 35, No. 6, 2010, pp. 990-994. doi:10.1016/j.jhsa.2010.03.012 